\title{
Competence, Motivation and Strategic Thinking of Bengkulu University Employees
}

\author{
Praningrum $^{1}$, Sugeng Susetyo ${ }^{2}$, Fachrudin J.S. Pareke ${ }^{3}$ \\ Faculty of Economics and Business - Bengkulu University ${ }^{1,2,3}$ \\ \{ praningrum@gmail.com \}
}

\begin{abstract}
The purpose of this research is to determine the effect of competence on the strategic thinking of Bengkulu University employees and motivation as a mediating variable. This type of research is descriptive quantitative, using a questionnaire as a data collection technique. The population in this study were all Bengkulu University employees, totaling 1128 people. Determination of respondents was using simple random sampling with a sample size of 110 people. The data analysis method used mediated regression analysis. The results showed that competence had a significant and positive effect on the strategic thinking of Unib employees, and intrinsic motivation had significant effect on strategic thinking and mediate partially competence to strategic thinking.
\end{abstract}

Keywords: Competence; Motivation; Strategic Thinking

\section{Introduction}

Strategic thinking is very important for an organization, because the ability to think strategically will produce strategic plans and can make the organization excel and have good performance. Strategic thinking is the ability to develop broadly, the big picture of the organization and its mission, the ability to connect long-term visions and concepts with everyday work, encompassing attention to stakeholders, market opportunities, emerging technologies, industry trends, threats and competitive advantage [1].

Strategic thinking is important, because it can improve individual performance [2], has a positive effect on decision making [3], environmental adaptation, and organizational career support [4], strengthens administrative aspects [5], increases competitiveness [6], improves marketing performance [7], increases efficiency, performance and effectiveness [8], and for the long-term success of the organization [9]. Strategic thinking is able to provide positive and significant results for organizations [10], [11], [12], [13].

Strategic thinking is influenced by individuals and organizations [14], influenced by motivation [15], [16], [17], workplace and educational levels of managers and personnel [18], managers who have a vision, the ability to analyze systems thinking, the ability to to ask, creativity, ability to create synergy and ability to create profit [19]. Although strategic thinking is important to the direction and sustainability of an organization, it has received significantly less attention. The gap in practice is fueled by a historical confusion of concepts between scholars and practitioners, where the terms strategic thinking, strategic planning, and strategic management are used interchangeably, and strategic thinking is referred to as nouns and verbs 
[20]. Lack of strategic thinking not only causes managers unable to maximize resources and critical times, it can also stop company operations [21].

During the last 25 years, research results have identified that if there is no decision to do strategic thinking by the leader, then the organizational performance is not good [20]. Three problems in strategic thinking, namely: 1) lack of understanding of the concept as a whole; 2) practitioners who constantly confuse the terms strategic thinking with strategic planning and other strategic, and 3) the development of limited strategic thinking among organizational leaders [22]. This problem raises the need to develop the strategic thinking skills of those at higher levels [23], because strategic management can be achieved if and only if managers have developed adequate strategic thinking [24].

Several studies have shown that strategic thinking is part of the abilities and skills required to perform strategic managerial tasks of business leaders and has an impact on strategy formulation and strategy implementation [18], and the formulation of knowledge-based strategies starts with the competence of people [25], [23], [20]. Competence related to strategic management, according to [26] is the intangible assets in the form of customer trust, company reputation, intellectual property, databases, network of connections inside and outside the company and competence, is a rather complex asset category, which is difficult to replicate and transfer from one company to another. Therefore, an adequate management strategy is needed, which can implement intangible assets and competencies in the market in order to create added value.

Competence alone is not enough, it must be accompanied by motivation, this is in accordance with the opinion of [27], which states that motivation is the basis for various behavior and individual performance, where motivation to behave can be influenced by two categories of motivation, namely intrinsic motivation and extrinsic motivation. Very little research has been done on the relationship between intrinsic motivation and strategic thinking [17], even strategic thinking has significant implications for the design of planning processes in organizations.

University of Bengkulu (Unib) is currently experiencing a national downgrade level. In 2016 it was ranked 35, 2017 it was ranked 45, 2018 it was ranked 48 and in 2019 it was ranked 64. Many factors have caused Unib's ranking to drop at the national level, physically it could be due to Unib's accreditation which is still B, the value of accreditation A study program is still limited, the qualifications of lecturers are not many who are professors and doctors, research work and dedication of lecturers and students are also limited, writing journal articles is also limited [28]. Non-physically, the possibility of downgrading is because the program planning at the university has not gone through strategic thinking which has significant implications for the design of the planning process in the organization.

The purpose of this study was to determine the effect of competence on strategic thinking through the mediation of intrinsic motivation. This research was conducted because of the opinion [12], that there is a need for further research that can help to better understand strategic thinking, and will gain an important missing link in strategic management research and allow for a more realistic picture between strategic decision makers and decision making.

\section{Literature Review}

\subsection{Strategic Thinking}

The traditional approach to strategic planning has become a thing of the past. Traditional 
processes have stifled initiative and paid more attention to improvement than substantive change, emphasizing analytics and extrapolation more than creativity and discovery, and ignoring consumers' voices. To overcome this problem, they argue that there is an important element, namely strategic thinking that is able to provide positive and significant results for the organization [10], [11], [12], [13].

Strategic thinking is presented as the development of thinking concepts, skills, styles and techniques, as visionary, intuitive and consistent, and the thinking that strategic thinking is the key to the foundation of corporate survival and that strategic thinking is essential for strategic planning [18]. Strategic thinking is an individual experience and takes place informally and without being followed by certain decisions or actions [13]. Strategic thinking is closely linked with acting in a continuous and interrelated process. Organizations that successfully develop and integrate strategic thinking at both the individual and organizational level can create core competencies on which to base competitive advantage. Seen from this perspective, the role of strategic thinking should be the center of attention for business progress in the future [24].

Strategic thinking is recognized as an individual activity; is another form of mental processing (conceptual, systems-oriented, directed, and opportunistic) which involves a series of recursive activities (scanning, questioning, conceptualization, and testing) to identify and plan organizational strategy and / or understand patterns that infer organizational strategy [29]. Strategic thinking is the process of finding patterns or common threads related to organizational activities that come from policies, goals, and objectives which consist of the dimension of reflection (the ability to make decisions based on one's rational thinking through experiences, by consolidating new data and previous data to find more feasible techniques), organizational awareness (understanding of the entire organization, the complexity of the relationships that occur between subsystems and their interactions with the outside world), trend analysis (a change from seeing the organization as separate and competing parts for resources, to seeing the company as a holistic system that integrating each part of the relationship as a whole) and pattern recognition (a skill to monitor, verify, and improve recognition outcomes in new and high-risk situations, when immediate action on an acknowledged response is not required [29].

\subsection{Competence}

The term competency is broadly associated with the results of McClelland's research, which states that individual competence is the ability to apply skills and knowledge, followed by several other researchers who define competence as: knowledge, skills, abilities, characteristics, motives, traits, attitudes, values, beliefs, interests, work habits, and aspects of self-image or social roles [20]. According to [30] a person must have competence, namely the presence of self-confidence to do activities and adapt to the external environment and the internal environment. Have the confidence to optimally complete challenging tasks and be able to achieve the desired results. Competence or effectiveness is one of the three basic psychological needs that can energize human activities and provide long-term psychological satisfaction and well-being.

Competency frameworks are usually seen as a mechanism for linking HR to organizational strategy. Competence is a descriptive tool that identifies the skills, knowledge, personal characteristics, and behaviors needed to effectively perform a role in an organization and help a business achieve its strategic goals [31]. Referring to the individual responsible for strategy, competence as a holistic concept consisting of technical, management, people, attitudes, values and mental skills components [32]. According to [33] competence can be classified into four 
aspects of professional, methodological, social, and self-competence, which cites Klemp and McClelland's opinion that defines competence as an individual attribute needed to produce effective performance both on the job and in one's role. These attributes include (1) general or specific knowledge used in work; (2) physical and intellectual abilities; (3) characteristics, such as energy levels and certain personality types; (4) motives or needs that lead individuals toward patterns. Desired behavior, and (5) self-image that reflects the role people see themselves and their concept of how effective they are in carrying out their roles. They also cite Campion's opinion which states that competence refers to the presence of knowledge, skills, abilities, and other characteristics (KSAo) required to obtain effective performance in someone's job.

\subsection{Motivation}

Motivation is the process of allocating cognitive resources in which a person makes choices regarding the time and energy to be allocated to various motives or tasks or processes that take into account the individual's intensity, direction, and endeavors to achieve goals. There are three important points to consider: passion, direction, and maintenance of a particular activity. Passion is a stimulus that makes activity possible. Direction is the action required to decide which goals to pursue and maintenance includes the power that continues to manifest until the goal is achieved. Motivation can be classified into intrinsic and extrinsic. Extrinsic motivation refers to external rewards given to individuals as a result of achieving certain goals and can usually be done through monetary considerations such as bonuses, incentives and promotions. While intrinsic motivation refers to a feeling of getting a job well done, the activity is motivation in itself [34].

Intrinsic motivation can be defined as motivation to carry out an activity for its own benefit, to experience the pleasure and satisfaction inherent in the activities it does [35], [36]. Intrinsic motivation is motivation to enjoy an activity purely for reasons of the activity itself. When individuals are intrinsically motivated, they practice activities for the benefit and pleasure provided by those activities and they usually perform at a relatively high level [37]. Extrinsic motivation is to act to obtain rewards or avoid punishment, and is done because personally, is important, will be appreciated, and means something to that person. Interpretation uses selfdetermination theory, that intrinsic goals are directly related to satisfaction with basic psychological needs. Meanwhile, extrinsic goals are indirectly related to or even contrary to the satisfaction of basic needs. The results of intrinsic motivation are good growth, and good relations with the community, while the results of extrinsic motivation are wealth and fame. If someone prioritizes extrinsic goals, then performance and welfare tend to be low, whereas if intrinsic goals are prioritized, performance and welfare tend to be better [38].

\subsection{Hypothesis}

One component of the formulation of a business strategy is strategic thinking [13], which is a cognitive process that can and must precede strategic decisions and actions. The way that can be done to develop strategic thinking is by providing competence, ability, skills, motivation, attitudes and values [39].

H1: Competence affects the strategic thinking of University of Bengkulu employees.

Employees can increase intrinsic motivation if they feel there is supervisor support for development, competence and autonomy [40]. The intrinsic motivation summarized [41] is as something that is pursued as inherently possible because it directly satisfies innate psychological 
needs such as a sense of belonging, personal reasons, as well as needs for connectedness, competence, and autonomy. The results of [42] showed that competence has a positive effect on intrinsic motivation.

$\mathrm{H} 2$ : Competence affects the motivation of the Bengkulu University employees.

If staff find their workplace enjoyable they will be committed and dedicated to their job; they will be motivated to work in unfavorable conditions and they will generate competitive advantage through strategic thinking and strategic planning [43]. While the results of the study [17] there is a positive relationship between intrinsic motivation, strategy use, and critical thinking.

H3: Intrinsic motivation affects the strategic thinking of Bengkulu University employees.

The way that can be done to develop strategic thinking is by providing competence, ability, skills, motivation, attitudes and values [39].

H4: Competence and intrinsic motivation influence strategic thinking of Bengkulu University employees

From the three hypotheses above, this study will examine the effect of competence on strategic thinking mediated by intrinsic motivation.

H5: Competence affects strategic thinking mediated by intrinsic motivation

\section{Methodology}

The type of this research is a quantitative descriptive study to obtain an overview of the motivation,knowledge management and performance of Bengkulu University employees. Collecting data using a questionnaire and a Likert measurement scale, with five alternative answers ranging from strongly agree (score 5) to strongly disagree (score 1). The question item for strategic thinking is the indicator put forward by [29]. The question item for motivation is an indicator from [40] and the competency question item uses the indicator by [44]. After testing, all questions are valid and reliable to be used as a research instr ument.

The population in this study were all lecturers and employees of Bengkulu University. The total population was 1128 people. Determination of respondents in this study was simple random sampling of $10 \%$ of the total population. Thus, the number of samples used in this study was 110 people, and data were obtained directly from the source or object of the research.

Data is analyzed using mediation model of [46] which focuses on the estimation of the indirect effect of Competence $(\mathrm{X})$ on Strategic Thinking $(\mathrm{Y})$ through an intermediary mediator variable Motivation (M) causally located between $\mathrm{X}$ and $\mathrm{Y}$, where $\mathrm{X}$ is the input variable, $\mathrm{Y}$ is output and $\mathrm{M}$ is the Mediating Variable. This model establishes two pathways which influences $\mathrm{Y}$ by direct effect and indirect effect. In direct effect, pathways lead from $\mathrm{X}$ to $\mathrm{Y}$ without passing M. In indirect effects, a pathway of $\mathrm{X}$ to $\mathrm{Y}$ is lead through M. There are three consequent variables forming three equations and these equations can be estimated by conducting OLS regression analyses using SPS.

\section{Results and Discussion}

\subsection{Characteristics of Respondents}

Based on the respondents' answers to the research questionnaire that had been collected and examined, it was obtained a description of the characteristics of the respondents that the majority 
of respondents were male, namely as many as 59 people $(53.64 \%)$. The age of the respondents was evenly distributed for each age group, aged 28-33 years $(17.27 \%$ ), and ages 58-63 years also amounting to $(17.27 \%)$. As for the characteristics of education levels, the majority of respondents qualify for S2, namely 97 people $(88.18 \%)$. In terms of years of service, the majority of respondents have worked more than 25 years.

\subsection{Respondents' Responses}

The average respondent's response to the strategic thinking variable at Unib is high, this shows that employees have the opportunity to have strategic thinking. The highest average is the dimension of reflection in which employees always try to find the same goal between two work fields or two parts of the organization. Employees think about the relationship between one unit and another and between one task and another that is different in the organization. Employees also know the role of the individual are in the larger system and understand that employee behavior affects work outcomes throughout the organization. The lowest average dimension is the average pattern recognition dimension, with indicators preferring to ignore short-term gains in order to achieve long-term profits. This means that they are think more for the long term, for success and good in the long term. If viewed per indicator, the highest indicator is that employees are aware of the strengths and weaknesses of the organization and know that each individual has an important role in a large system and understands that each individual and their behavior has an influence and impact on the work results of all Unib organizations.

Respondents' response to the average intrinsic motivation is very high, they state that work means a lot to them, the tasks performed at work are very attractive and are a driving force in carrying out work, and feel very fortunate to be paid for their work. They are serious about their work and do not consider it a mere hobby. The work done by individuals has an important meaning for themselves, the organization and their life in general.

Respondents' responses to competency variables has show a high average. This means is that Bengkulu University employees have high knowledge and skills that can be used to complete their work. The highest indicator is where employees feel competent in carrying out their work. However, to carry out difficult tasks is below average, where employees find it difficult to complete work that is not in accordance with their competence.

\subsection{Results}

In the first stage carried out in this study is simple regression between the independent variable $(\mathrm{X})$ on the dependent variable $(\mathrm{Y})$. Using SPSS, the regression equation for the effect of competence on strategic thinking is obtained:

$\mathrm{Y}=0.425 \mathrm{X}$.

The regression results show that competence has a positive and significant effect on strategic thinking, with a coefficient of $\beta 0.425$ and a significance level of $0.000<0.05$. In this first stage, it supports hypothesis 1 (first) which gives the conclusion that competence has a significant positive effect on strategic thinking. This proves that the higher the employee's competence, the higher the level of thinking.

The second stage is a simple regression analysis between the independent variable $(\mathrm{X})$ and the mediating variable $(\mathrm{M})$. The regression equation for the effect of competence on intrinsic motivation: 
It can be explained that competence has a positive effect on motivation, with a coefficient value of $\beta 0.439$ and a significance value of $0.000<0.05$. This second stage supports hypothesis 2 (second) which results in the conclusion that competence has a significant positive effect on motivation. In this case it can be concluded that the higher the competence, the higher the level of employee motivation.

In the next stage, it is done by simply regressing the influence of the mediating variable (M) and the dependent variable (Y). In this study, the mediating variable is intrinsic motivation and the dependent variable is strategic thinking, the results of the SPSS output are obtained with the regression equation of the influence between the motivation and strategic thinking variables:

$\mathrm{Y}=0.495 \mathrm{M}$.

It shows that intrinsic motivation has a positive effect on strategic thinking, with a value coefficient of $\beta 0.495$ and a significance level of $0.000<0.05$. In this third stage, it supports hypothesis 3 (third) that intrinsic motivation affects strategic thinking. It can be concluded that the higher the intrinsic motivation level of an employee, the higher the employee's strategic thinking.

Furthermore, the fourth stage in this research is by simply regressing the influence of the independent, dependent and mediating variables. The independent variable in this study is competence with the dependent variable of this study, namely strategic thinking, then mediated by the mediating variable of intrinsic motivation, it is obtained that multiple regression equations have the effect of the competency variable on strategic thinking by including the intrinsic motivation variable as the mediating variable, namely as follows:

$\mathrm{Y}=0.257 \mathrm{X}+0.382 \mathrm{M}$

Based on the results of regression analysis through calculations using SPSS 16, the existing analytical framework can be described with the regression result values as follow:

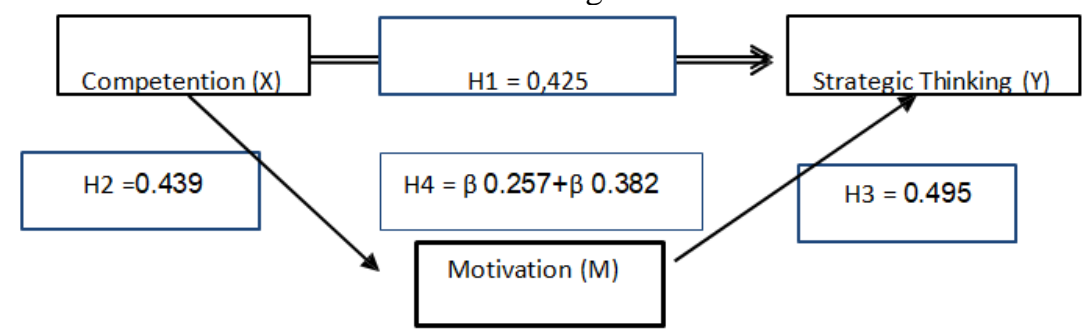

Fig. 1. Results of Mediated Regression Analysis

\subsection{Hypothesis Testing}

To determine whether there is direct or indirect influence of the independent variable on the dependent variable through the mediating variable, hypothesis testing is carried out. The mediation approach proposed by [45] explains, to see the significance of the indirect effect, this method is used even if the independent variable to the mediation variable is significant and the mediation variable to the dependent variable is also significant, but the difference in the value of the effect will increase or decrease (greater than 0). So it can be assumed that there is an indirect influence between the independent variable on the dependent variable or there is mediation. While the direct effect simultaneously (F-count value) and for the direct effect 
partially, the researcher used the causal steps test method with the condition that $\mathrm{Ha}$ was accepted if the significance was $<0.050$ [46].

Based on the results of the regression analysis that has been carried out, it can be seen that the intrinsic motivation variable is stated as a partial mediation variable, this is because after entering the intrinsic motivation variable, the influence of competence on strategic thinking on employees decreases to $\beta=0.257$ from the previous $\beta=0.425$ but not becomes zero $(\beta \neq 0)$. In addition, the influence of the competency variable on strategic thinking that was previously significant ( $\mathrm{p}$-value $0.000<0.05$ ) (before including the intrinsic motivation variable) and after entering the mediating variable intrinsic motivation into the regression equation model remained significant ( $\mathrm{p}$-value $0.005<0.050$. ). This means that testing the fourth hypothesis are proves that the existence of the intrinsic motivation variable on strategic thinking forms a significant influence and partially mediates. This means that competence is able to directly influence strategic thinking without going through motivation.

\subsection{Discussion}

The results showed that the first hypothesis in this study was accepted. It is known that the competency variable has a significant positive effect on the strategic thinking of Unib employees. This shows that the more a person's competence increases, the more his strategic thinking will increase. This is in line with the opinion [45] that the way that can be done to develop strategic thinking is by providing competencies, abilities, skills, motivation, attitudes and values.

Based on the results of the calculation, it is known that competence has a positive and significant effect on intrinsic motivation, meaning that the higher the competence of employees, the higher the level of intrinsic motivation. The results of the study are in line with the results of research [42], which shows that competence has a positive effect on intrinsic motivation and [40] states that employees can increase intrinsic motivation if they feel there is supervisor support for development, competence and autonomy. Intrinsic motivation has a positive effect on strategic thinking, meaning that the higher the level of intrinsic motivation of an employee, the higher the strategic thinking. This is in line with the opinion [17] that there is a positive relationship between intrinsic motivation, strategy use, and strategic thinking.

Based on the results of the calculation of $\mathrm{F}$ count (competence and intrinsic motivation), the value of 22,737 , the probability level is 0,000 , which is smaller than the alpha probability of 0.05 , this shows that competence and intrinsic motivation jointly influence strategic thinking in Bengkulu University employees. In line with the opinion [39] states that the way that can be done to develop strategic thinking is by providing competencies, abilities, skills, motivation, attitudes and values.

From the results of data processing using mediated regression, competency and intrinsic motivation variables affect strategic thinking. The role of intrinsic motivation is sufficient in mediating the influence of competence on employees' strategic thinking. Intrinsic motivation forms a significant influence on strategic thinking and mediates partially (partially mediation). This means that competence is able to directly influence strategic thinking, if through motivation it will have a greater influence, and without going through motivation competence will still have a significant effect.

\section{Conclusions}


Competence and intrinsic motivation have a significant positive effect on strategic thinking of Unib employees. Intrinsic motivation has a significant effect on strategic thinking and partially mediates. This means that competence is able to directly influence strategic thinking, if through motivation it will have a greater effect, and without going through motivation, competence will still have a significant effect.

Competence is an important factor for individuals to be able to increase motivation and strategic thinking, thus Unib is obliged to improve the competence of its employees. Competency enhancement can be done through the obligation to attend further studies and periodic training. Increasing competence can directly increase the knowledge, skills and abilities of employees as well as increase insight in their field of work, this of course can increase their motivation and willingness to do work more easily. In the end, it will encourage individuals to be willing to think for the success of the institution before planning and other strategic actions in starting strategic planning by all Bengkulu University employees.

\section{References}

[1] OECD, Competency Framework (2014).

[2] Mahdavian Mahdi, Mirabi Vahid Reza dan Haghshenas Farideh. A study of the impact of strategic thinking on the performance of Mashhad municipal Managers. Management Science Letters 4 (2014)

[3] Matar H.M., \& Samour A. A. Research Submitted In Partial Fulfillment Of The Requirement For The Degree Of Master Of Business Administration (2015).

[4] Kiaei, M. Z., Hatam, N., Moraveji, M., Moradi, R., Ahmadzadeh, M. S., \& Ghanavati, $\mathrm{S}$. The relationship between strategic thinking and hospital managers'productivity in teaching hospitals of shiraz (2016).

[5] Kalhori Morteza, \& Reza Shahhoseini. The effect of strategic thinking on administrative health Indian Journal Of Fundamental And Applied Life Sciences ISSN: 2231- 6345 (Online) Vol. 5 (S3), Pp. 1992-2003 (2014)

[6] Al-Hawary Sulieman, Ibraheem Shelash, Hadad Thaer, Fahmi Salim. The Effect Of Strategic Thinking Styles On The Enhancement Competitive Capabilities Of Commercial Banks In Jordan International Journal Of Business And Social Science Vol. 7, No. 10; pp 133 (2016)

[7] Byeong-Joonmoon. Antecedents And Outcomes Of Strategic Thinking. Journal Of Business Research.Volume 66, Issue 10, October 2013, Pages 1698-1708, (2012)

[8] Nuntamanop P., \& Kauranen I., Igel B. A New Model Of Strategic Thinking Competency, Journal Of Strategy And Management, Vol. 6 Issue: 3, Pp.242-264(2013)

[9] Self Dennis R, Terry Self Tish, Matuszek Mike Schraeder. Improving organizational alignment by enhancing strategic thinking, Development and Learning in Organizations: An International Journal, 29 (1), 11 - 14. (2015).

[10] Mintzberg, Henry. The Rise And Fall Of Strategic Planning. Basic Books. (1994).

[11] Liedtka, Jeanne. M. Strategic Thinking: Can it be Taught? Long Range Planning, 31 (1), 120-129 (1998).

[12] Bonn, Ingrid. Improving strategic thinking: a multilevel approach. Leadership \& Organization Development Journal, 26 (5), 336 - 354, (2005).

[13] Tavakoli I. \& Lawton J. Strategic thinking and knowledge management. Handbook of Business Strategy, 6, (1) 155 - 160. (2005).

[14] Alimi D. Ali. Ranking The Key Factors Of Success In Strategic Thinking And 
Management By Using MCDM-FAHP Technique. JIEB 9 (5): 4332-4340. (2016).

[15] Brătianu C. Developing Strategic Thinking In Business Education Management Dynamics In The Knowledge Economy. Vol.3 (2015) No.3, Pp.409-429 (2015).

[16] Jain Priti. Strategic human resource development in public libraries in Botswana. LibraryManagement, 26 (6/7), 336 - 350.(2005).

[17] Garcia T., \& Pintrich P. R. Brief Research Report The Effects Of Autonomy On Motivation And Performance In The College Classroom. Contemporary Educational Psychology 21, 477-486 (1996) [18] Salavati, Veshareh, Safari, Veysian, \& Amirnezhad. Strategic thinking and its related factors in a medical science university in Iran. Electronic Physician. Volume: 9, Issue: 5, Pages: 4332-4340. (2017).

[19] Kalali Nader Seyed, Momeni Mansoor, Heydari Elham Key Elements Of Thinking Strategically. International Journal Of Management, Accounting And Economics Vol. 2, No. 8, August, 2015 ISSN 2383-2126, (2015)

[20] Goldman Ellen, Scott Andrea Richards, Competency Models For Assessing Strategic Thinking, Journal Of Strategy And Management, Vol. 9 Issue: 3, Pp.258-280 (2016).

[21] Howarth R., What is Strategic Thinking? President of the Strategic Thinking Institute. (2009).

[22] Goldman E. F. \& Casey A.. Building A Culture That Encourages Strategic Thinking Journal Of Leadership \& Organizational Studies 17(2) 119-128 (2010)

[23] Goldman Ellen F. Leadership practices that encourage strategic thinking, Journal of Strategy and Management, Vol. 5 Issue: 1, pp.25-40, (2012).

[24] Bonn, Ingrid. Developing strategic thinking as a core competency. Management Decision, 39 (1), 63 -71.(2001).

[25] Sveiby Karl-Erik. Knowledge-based theo ry of the firm to guide strategy. Journal of Intellectual Capital. Vol 2, Nr 4. (2001)

[26] Fahy J., The resource-based view of the firm: some stumbling-blocks on the road to understanding sustainable competitive advantage, Journal of European Industrial Training, Vol. 24 Iss 2/3/4 pp. $94-104$, (2000)

[27] Law, K. K., Chan, A., \& Ozer, M. (2017). Towards an integrated framework of intrinsic motivators, extrinsic motivators and knowledge sharing. Journal of Knowledge Management

[28] Tyo, (2019).

[29] Dhir S., Dhir S., Samanta P. Defining and developing a scale to measure strategic thinking, Foresight, Vol. 20 Issue: 3, pp.271-288, (2018).

[30] Deci, E. L.,\& Ryan, R. M. Intrinsic motivation and self-determinationin human behavior. New York: Plenum. (1985).

[31] Le Deist F.D \& Winterton Jonathan. What Is Competence? Human Resource Development International, Routledge Francis Taylor Group. Vol. 8, 1, 27 - 46(2005).

[32] Garavan dan McGuire (2001)

[33] Meyer Gerrit, Brünig Bianca, Nyhuis Peter, Employee Competences In Manufacturing Companies -An Expert Survey", Journal Of Management Development, Vol. 34 Issue: 8, Pp.1004-1018, (2015)

[34] Jalagat Revenio Job Performance, Job Satisfaction, and Motivation: A Critical Review of their Relationship. International Journal of Advances in Management and Economics. ISSN: 2278-3369 Vol.5| Issue 6|36-42, (2016)

[35] Deci, E. L., Connell, J. P., \& Ryan, R. M. Self-determination in a work organization. Journal of applied psychology, 74(4), 580. (1989). 
[36] Vallerand, R. J. Toward a hierarchical model of intrinsic and extrinsic motivation. In Advances in experimental social psychology (Vol. 29, pp. 271-360). Academic Press. (1997).

[37] Makki dan Abid Influence of Intrinsic and Extrinsic Motivation on Employee's Task Performance Studies in Asian Social Science Vol. 4, No. 1; 2017 pp 38-43. (2017)

[38] Deci Edward L. \& Ryan Richard M. Motivation, Personality, and Development Within Embedded Social Contexts: An Overview of Self-Determination Theory The Oxford Handbook of Human Motivation. Oxford University Press., Edited by Richard M. Ryan. (2012).

[39] Goldman, Ellen F. Scott, Andrea R. Follman Joseph M., Organizational practices to develop strategic thinking, Journal of Strategy and Management, Vol. 8 Issue: 2, pp.155175. (2015).

[40] Kuvaas Bård. (2008). A test of hypotheses derived from self-determination theory among public sector employees. Employee Relations, 31 (1), 39 - 56.

[41] Sheldon Kennon M, Ryan Richard M., Deci Edward L. \& Kasser Tim. The Independent Effects of Goal Contents and Motives on Well-Being: It's Both What You Pursue and Why You Pursue It. Personality And Social Psychology Bulletin, 30 (4), 475 - 486. (2004).

[42] Painter Jason. Autonomy, competence, and intrinsic motivation in science education: a self determination theory perspective. A dissertation submitted to the faculty of the University of North Carolina at Chapel Hill. (2011).

[43] Jain Priti, (2005). Strategic human resource development in public libraries in Botswana. LibraryManagement, 26 (6/7), 336 - 350.

[44] Broeck, Vansteenkiste D,. W, Soenensand \& Lens. Capturing autonomy, competence, andrelatedness at work: Construction and initial validation of the Work-related Basic Need Satisfaction scale. Journal of Occupational and Organizational Psychology (2010), 83, 981-1002 (2010).

[45] Baron, R. M., \& Kenny, D. A. The moderator-mediator variable distinction in social psychological research: Conceptual, strategic, and statistical considerations. Journal of Pe nality and Social Psychology, 51(6), 1173-1182.(1986).

[46] Hayes AF. Introduction to Mediation, Moderation, and Conditional Process Analysis: A Regression- Based Approach. New York, NY: The Guilford Press; 201 